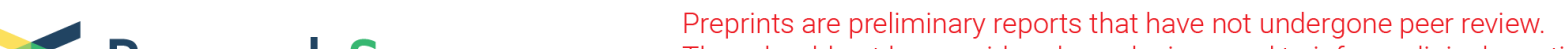 Research Square
or referenced by the media as validated information.
}

\section{Pleural and pulmonary dissemination patterns from gastric adenocarcinoma among patients with treated primary disease in Latin-America.}

\section{Juliana Restrepo}

Instituto Nacional de Cancerologia

Carlos Andrés Carvajal Fierro ( $\sim$ ccarvajalmd@gmail.com )

Instituto Nacional de Cancerología https://orcid.org/0000-0001-5915-0052

Helena Facundo

Instituto Nacional de Cancerologia

Felipe Gonzalez

Instituto Nacional de Cancerologia

Ana María Ramirez

Instituto Nacional de Cancerologia

Rafael Beltrán

Instituto Nacional de Cancerologia

Ricardo Buitrago

Instituto Nacional de Cancerologia

Andrés Felipe Jiménez

Instituto Nacional de Cancerologia

José Carreño

Instituto Nacional de Cancerologia

Ricardo Oliveros

Instituto Nacional de Cancerologia

\section{Research Article}

Keywords: Stomach Neoplasms, Lymphatic Metastasis, Neoplasm Metastasis, Solitary Pulmonary Nodule, Multiple Pulmonary Nodules

Posted Date: February 21st, 2022

DOI: https://doi.org/10.21203/rs.3.rs-960387/v1

License: (c) (1) This work is licensed under a Creative Commons Attribution 4.0 International License.

Read Full License 


\section{Abstract}

Background: Latin-America is one of the regions with the highest incidence of gastric cancer. Even though, there are not reports about the patterns of pleural and pulmonary metastases in patients with gastric adenocarcinoma treated with curative intent and the prognosis according to each dissemination pattern.

Methods: retrospective cohort study at the Instituto Nacional de Cancerología-Colombia.

Results: the study included 450 patients, $51.3 \%$ were male and the median age was 63 years. Intestinal adenocarcinoma was the most frequent histological subtype, in 261 cases (58.0\%). Gastric cancer initial pathological stage was stage I in $23.3 \%$ of the patients, stage II in $19.3 \%$ and stage III in $53.6 \%$. During a median follow-up of 31.9 months, 37(8.2\%) patients developed lung or pleural abnormalities; among those, $14(3.1 \%)$ met the criteria for pleuro-pulmonary metastases: $6(1.3 \%)$ had lymphangitic metastasis, $4(0.9 \%)$ had a mixed pattern of pleural and lung nodules, $3(0.7 \%)$ had pleural metastasis, and only one $(0.2 \%)$ had hematogenous metastasis. The median overall survival was 114.5 months for the entire cohort and $38.2(95 \% \mathrm{Cl}, 19.2-57.2)$ months for patients with pleuro-pulmonary metastases. Patients with pleural metastasis and lymphangitic carcinomatosis had median survival of $24.3(95 \% \mathrm{Cl}, 0.01-51.0)$ and $26.4(95 \% \mathrm{Cl}, 18.2-34.7)$ months, respectively.

Conclusions: incidence of pleuro-pulmonary metastases in patients with gastric adenocarcinoma treated with curative intention was low. In our series, lymphangitic carcinomatosis was the main pattern of dissemination; meanwhile, hematogenous metastasis was rare and patients with pleural carcinomatosis had the lowest median survival. These findings and their prognosis were different compared to those reported in Eastern countries.

\section{Background}

In 2020, the GLOBOCAN estimated an age-standardized incidence rate (ASIR) of 11.1 and mortality rate of 7.7 per 1000.000 population, making this cancer the fifth and fourth in terms of frequency and mortality, respectively [1]. In Colombia, Pardo et al. described in 2018 an ASIR in men of 18.5 per 100.000 population corresponding to second place in frequency and in women of 10.3 per 100.000 population occupying fourth place. Meanwhile, the age-standardized cancer mortality rate (ASMR) in men was 14.2, representing the leading cause of cancer deaths [2]. The stage at diagnosis in our country is different from those reported in eastern countries where most patients are diagnosed in early stages of the disease due to screening programs.

The recurrence rate of gastric cancer patients treated with complete surgical resection is between $30 \%$ and $50 \%$, generally occurring within the first two years after gastrectomy [3], and distant recurrence is present in more than $50 \%$ of cases [4]. According to Kong et al. [5], hematogenous pattern of lung metastasis was the main pattern of dissemination with almost $45 \%$ of the 193 patients with pleuro- 
pulmonary metastasis in their study that included 20.187 patients with early to advanced or metastatic gastric cancer in Korea.

Even though, America occupies third place in gastric cancer incidence, after Asia and Europe [6]; there are not reports about the patterns of pleural and pulmonary metastases in these patients. This study aimed to identify pleural and pulmonary dissemination patterns in patients with gastric adenocarcinoma treated with curative intent at Instituto Nacional de Cancerología (INC) in Colombia. Our findings will allow us to define the prognosis according to each dissemination pattern and to understand the disease biology in a more comprehensive way.

\section{Methods}

This retrospective cohort study included patients with gastric adenocarcinoma treated with curative intent. Patients were diagnosed and treated at INC between January 2010 and July 2017 and were selected from the database, comprising the total and subtotal gastrectomies. Clinical records were reviewed, and patients younger than 18 years, with metastatic disease at diagnosis, with tumors of the esophago-gastric junction (Siewert classification I and II), with positive surgical resection margins, or those with positive peritoneal fluid cytology were excluded. A pre-designed RedCap 7.1.2 $\odot$ format was used to collect the data. Age and sex were analyzed as demographic variables, and the variables for the primary disease included were location, stage, gastric surgery performed, histologic subtype, and other histologic variables like perineural invasion and linfovascular invasion. Variables associated with the pleural or pulmonary disease progression, such as the type of pleuro/pulmonary compromise, were also analyzed and, when pulmonary nodules were present, the number, radiologic characteristics, size, location, and histology were described. Other variables included were the treatment received by the patient (i.e. adjuvant chemotherapy or palliative chemotherapy) and, in the cases where pulmonary resection was performed; we also assessed the type of surgery. Concomitant metastatic sites were not described in the present study.

Lung and pleural surveillance protocol of gastric cancer patients treated with curative intent includes CTScan every 6 months for 2 years after surgery and annually thereafter for the next 3 years. Respiratory symptoms at any time of follow-up indicate CT-Scan.

A data monitoring group at INC validated the information from a representative sample of patients to assess their validity. The data were analyzed using SPSS Vr. 17. Descriptive statistics were used to report the medians and interquartile range (IQR) of continuous variables (25th and 75 th centiles given as the IQR). Number and percentage were used to describe categorical variables. Survival curves were presented using the Kaplan Meier method and compared using the log-rank test. Overall survival was defined as the time elapsed in months between surgery with curative intent for gastric cancer and the date of death or the last follow-up. The confirmation of the vital status of each patient was made quarterly, and they were considered as censored data when the follow-up time of a patient ended before death or before completing the observation period, when survival times could not be accurately established or when the 
patient died from causes unrelated to the event of interest. A univariate analysis was done to determine the risk factors associated with the presence of pleural and pulmonary metastases. The ethics committee at our institution approved the protocol before collecting the patient's data, Act No. 0023-19.

Hematogenous metastasis was defined as solitary or multiple lung nodules on Computed Tomography (CT) scan, in patients who underwent resection and had histopathologic confirmation. Nodules with a benign histopathologic report or stability in the follow-up on the CT-scan were not classified as hematogenous metastases. Pleural metastasis was defined as pleural thickening or effusion on CT-scan or chest X-ray with histopathologic confirmation or highly suspicious CT-scan findings. Lymphangitic metastasis was defined as interstitial patterns such as thickening or irregularity of interlobular septa and bronchovascular bundles on CT-scan consistent with lymphangitic carcinomatosis. Histopathologic confirmation was not mandatory.

\section{Results}

We found 450 patients with gastric adenocarcinoma treated with curative intent and negative surgical resection margins; male gender was predominant, with $51.3 \%$ of the patients being male and having a median age of 63 years (IQR 53 - 71). The gastric tumor location was cardial in 62 patients (13.8\%) and non-cardial in 386 (85.8\%). The type of gastric surgeries performed were subtotal gastrectomy in 216 patients (48.0\%) and total gastrectomy in $202(44.9 \%)$, see Table 1. Intestinal adenocarcinoma was the most frequent histological subtype, observed in 261 cases (58.0\%), followed by diffuse in 116 cases (25.8\%) and mixed in 45 cases (10.0\%). Perineural invasion (PNI) of the gastric tumor was reported in 235 cases (52.2\%) and lymphovascular invasion (LVI) in 296 (65.8\%). Human epidermal growth factor receptor 2 (HER2) status was assessed by immunohistochemistry (IHC) in 190 patients, and overexpression was found in 17 of them (8.9\%), see Table 1. 
Table 1

Demographic, gastric cancer, surgical and follow-up variables.

\begin{tabular}{|ll|}
\hline Variable (n=450) & No (\%)/median (IQR) \\
\hline Age (years) & $63(53-71)$ \\
\hline Male & $231(51.3)$ \\
\hline Primary tumor variables & \\
\hline Location (missing data: 2) & $386(85.8)$ \\
Non-cardial & $62(13.8)$ \\
Cardial & \\
\hline Type of gastric surgery & $216(48.0)$ \\
Subtotal gastrectomy & $202(44.9)$ \\
Total gastrectomy & $32(7.1)$ \\
Total gastrectomy with esophageal margin & \\
\hline Stage * & $105(23.3)$ \\
I & $87(19.3)$ \\
II & $241(53.6)$ \\
III & $17(3.8)$ \\
Incomplete lymph node count & $296(65.8)$ \\
Histologic subtype, (missing data: 28$)$ & $235(52.2)$ \\
Intestinal & $17(8.9)$ \\
Diffuse & $116(25.8)$ \\
Mixed & $45(10.0)$ \\
\hline Lymphovascular invasion (missing data: 78$)$ & $268.0)$ \\
\hline HER 2 positive (missing data: 260) & \\
\hline
\end{tabular}

*Stage AJCC 2018. 


\begin{tabular}{|c|c|}
\hline Variable $(n=450)$ & No (\%)/median (IQR) \\
\hline \multicolumn{2}{|l|}{ Additional treatments } \\
\hline Neoadjuvant chemotherapy & $34(7.6)$ \\
\hline Adjuvant chemotherapy & $298(66.2)$ \\
\hline Palliative chemotherapy & $45(10.0)$ \\
\hline Neoadjuvant radiotherapy & $14(3.1)$ \\
\hline Adjuvant radiotherapy & $209(46.4)$ \\
\hline Palliative radiotherapy & $11(2.4)$ \\
\hline Median size of pulmonary nodules (mm.) & $8(3-27)$ \\
\hline Patients taken to pulmonary nodule resection & $n=8$ \\
\hline \multicolumn{2}{|l|}{ Type of pulmonary resection } \\
\hline Wedge resection & $6(75.0)$ \\
\hline Anatomic segmental resection & $1(12.5)$ \\
\hline Lobectomy & $1(12.5)$ \\
\hline \multicolumn{2}{|l|}{ Number of nodules resected per patient, (n: 8) } \\
\hline 1 & $4(50.0)$ \\
\hline 2 & $4(50.0)$ \\
\hline \multicolumn{2}{|l|}{ Histology of the resected nodules, (n: 8) } \\
\hline Benign nodule & $6(75.0)$ \\
\hline Primary pulmonary adenocarcinoma & $1(12.5)$ \\
\hline Gastric cancer metastasis & $1(12.5)$ \\
\hline \multicolumn{2}{|l|}{ Follow up variables } \\
\hline Patients with $<6$ months of follow up & $55(12.2)$ \\
\hline Patients with 6 to 12 months of follow up & $54(12.0)$ \\
\hline Patients with 12 to 24 months of follow up & $67(14.9)$ \\
\hline Patients with 24 to 36 months of follow up & $69(15.3)$ \\
\hline Patients with $>36$ months of follow up & $205(45.6)$ \\
\hline
\end{tabular}

Gastric cancer initial pathological stage was stage III in 241 cases (53.6\%), stage II in 87 (19.3\%), and stage I in 105 (23.3\%). Neoadjuvant and adjuvant treatment with chemotherapy and radiotherapy is 
The median follow-up time was 31.9 months (IQR 12.4 - 57.9 months), being over 36 months in 205 patients (45.6\%) and below 6 months in 55 patients (12.2\%). While 413 patients (91.8\%) did not develop lung or pleural abnormalities, these abnormalities were observed in 37 of them (8.2\%). We found multiple lung nodules in 17 patients (3.8\%), lymphangitic carcinomatosis in $6(1.3 \%)$, solitary lung nodule in 6 $(1.3 \%)$, mixed pattern of lung nodules and pleural metastases in $4(0.9 \%)$, pleural metastasis in $3(0.7 \%)$ and non-specific lung opacities in one. Among these 37 patients, $14(3.1 \%)$ met the criteria for pleural or pulmonary metastases. $6(1.3 \%)$ had lymphangitic metastasis, $4(0.9 \%)$ had a mixed pattern of pleural and lung nodules, $3(0.7 \%)$ had pleural metastasis, and only one $(0.2 \%)$ had hematogenous metastasis, Figure 1. None of the patients with lymphangitic carcinomatosis and with mixed pattern on the CT-scan underwent surgical confirmation, since they met the criteria for metastasis. Pleural metastases were confirmed by histology and the patient with hematogenous metastasis had multiple lung nodules and was confirmed by wedge resection. Among the 23 patients with lung or pleural abnormalities that did not met the criteria for metastases, one had a solitary lung nodule and it's etiology was lung cancer, the other lesions were considered benign by histopathologic confirmation or stability on the CT-scan in the followup. The size and number of resected pulmonary nodules are described in Table 1.

The median overall survival was 114.5 months $(95 \% \mathrm{Cl}, 81.6-147.4)$ for patients with gastric adenocarcinoma treated with curative intent, and their 3-year and 5-year overall survival was $75 \%$ and $65 \%$, respectively, see Figure 2 . The median time for developing pleuro-pulmonary metastasis after gastric surgery was 22.3 months (IQR 9.5 - 28.3) and the median survival was 38.2 months $(95 \% \mathrm{Cl}, 19.2$ 57.2 ), 3 -year and 5 -year overall survival was $53 \%$ and $18 \%$ for patients with pleural or pulmonary metastases, respectively. On the other hand, the median survival after the diagnosis of pleuro-pulmonary metastasis was 1.1 months (IQR $0.1-22.6$ months). Patients with pleural carcinomatosis had the lowest median survival, 24.3 months $(95 \% \mathrm{Cl}, 0.01-51.0)$; followed by patients with lymphangitic carcinomatosis with a median survival of $26.4(95 \% \mathrm{Cl}, 18.2-34.7)$ and patients with mixed progression that had a median survival of $54.1(95 \% \mathrm{Cl}, 46.7-61.4)$, see Figure 2 . The only patient with hematogenous metastasis to the lung parenchyma survived 32.2 months.

Univariate analysis was performed to assess the variables associated with the presence of pleural or pulmonary metastases. None of the demographic or primary tumor characteristics were associated with gastric adenocarcinoma progression to the pleural space or the lung, see Table 2. 
Table 2

Univariate analysis for the risk factors for pleuro-pulmonary metastasis among patients with gastric adenocarcinoma treated with curative intent.

\begin{tabular}{|c|c|c|c|c|}
\hline Variable & $\begin{array}{l}\text { Pleuro-pulmonary } \\
\text { metastasis absent }\end{array}$ & $\begin{array}{l}\text { Pleuro-pulmonary } \\
\text { metastasis present }\end{array}$ & $\begin{array}{l}\mathrm{RR}(95 \% \\
\mathrm{Cl})\end{array}$ & $\begin{array}{l}\mathrm{p} \\
\text { value }\end{array}$ \\
\hline \multicolumn{2}{|l|}{ Age (years) } & & \multirow{3}{*}{$\begin{array}{l}0.9(0.59- \\
1.45)\end{array}$} & \multirow[t]{3}{*}{0.73} \\
\hline$<40$ & 23 & 37 & & \\
\hline$\geq 40$ & 390 & 0 & & \\
\hline \multicolumn{2}{|l|}{ Sex } & 24 & \multirow{3}{*}{$\begin{array}{l}0.95(0.78- \\
1.16)\end{array}$} & \multirow[t]{3}{*}{0.65} \\
\hline Male & 207 & \multirow[t]{2}{*}{13} & & \\
\hline Female & 206 & & & \\
\hline \multicolumn{2}{|l|}{ Location } & 32 & \multirow{3}{*}{$\begin{array}{l}1.00(0.74- \\
1.32)\end{array}$} & \multirow[t]{3}{*}{1} \\
\hline Non-cardial & 354 & 5 & & \\
\hline Cardial & 57 & & & \\
\hline $\begin{array}{l}\text { Stage of primary } \\
\text { disease * }\end{array}$ & & 4 & - & 0.82 \\
\hline \multirow{2}{*}{ I } & 101 & 7 & \multirow{2}{*}{$\begin{array}{l}1.04(0.77- \\
1.44)\end{array}$} & \multirow[t]{3}{*}{0.70} \\
\hline & 80 & \multirow[t]{2}{*}{21} & & \\
\hline "1 & 220 & & $\begin{array}{l}1.05(0.82- \\
1.33)\end{array}$ & \\
\hline \multicolumn{2}{|l|}{ Histology subtype } & 24 & - & 0.86 \\
\hline Intestinal & 237 & 8 & \multirow{2}{*}{$\begin{array}{l}1.02(0.8- \\
1.29)\end{array}$} & \multirow[t]{3}{*}{0.80} \\
\hline Diffuse & 108 & 2 & & \\
\hline Mixed & 43 & & $\begin{array}{l}1.05(0.74- \\
1.46)\end{array}$ & \\
\hline \multirow{2}{*}{$\begin{array}{l}\text { Lymphovascular } \\
\text { invasion }\end{array}$} & & 3 & \multirow{4}{*}{$\begin{array}{l}1.05(0.8- \\
1.37)\end{array}$} & \multirow[t]{4}{*}{0.71} \\
\hline & 73 & 27 & & \\
\hline NO & 269 & & & \\
\hline Yes & & & & \\
\hline \multirow[t]{2}{*}{$\begin{array}{l}\text { Perineural } \\
\text { invasion }\end{array}$} & & 5 & \multirow[t]{3}{*}{$\begin{array}{l}1.03(0.76- \\
1.37)\end{array}$} & \multirow[t]{3}{*}{0.86} \\
\hline & 64 & 24 & & \\
\hline 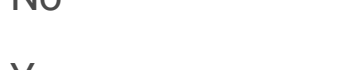 & 211 & & & \\
\hline
\end{tabular}




\begin{tabular}{|lllll|}
\hline Variable & $\begin{array}{l}\text { Pleuro-pulmonary } \\
\text { metastasis absent }\end{array}$ & $\begin{array}{l}\text { Pleuro-pulmonary } \\
\text { metastasis present }\end{array}$ & $\begin{array}{l}\text { RR (95\% } \\
\text { Cl) }\end{array}$ & $\begin{array}{l}\text { p } \\
\text { value }\end{array}$ \\
\hline $\begin{array}{l}\text { Adjuvant } \\
\text { chemotherapy }\end{array}$ & & 4 & $1.08(0.87-$ & 0.47 \\
No & 135 & 31 & $1.33)$ & \\
Yes & 267 & & & \\
\hline *Stage AJCC 2018, ** & & & & \\
\hline
\end{tabular}

\section{Discussion}

In this retrospective cohort study, the percentage of patients who developed lung or pleural abnormalities was $8.2 \%$ during a median follow-up of 31.9 months. However, of these patients, only $3.1 \%$ had pleural or pulmonary metastases, according to highly suspicious findings in the images or histopathologic confirmation. Most of these patients had lymphangitic carcinomatosis and pleural metastases. Only one patient with multiple lung nodules had metastasis from gastric adenocarcinoma, and none of the patients with solitary nodules had hematogenous metastasis, meaning that only $0.2 \%$ of this cohort had metastatic nodules in the lung parenchyma. These results are consistent with the fact that the etiology of new pulmonary nodules in the follow-up of gastric cancer patients with previous curative management is not related to metastatic histology. The latter is the reason why it is important to understand the incidence of pleuro-pulmonary metastases in gastric cancer patients treated with curative intent.

As expected, patients with pleuro-pulmonary progression of the disease had lower overall survival, and among them, there was a tendency towards a lower overall survival in patients with pleural carcinomatosis. The former finding was not statistically significant, probably due to the low incidence, resulting in a lack of statistical power for pleuro-pulmonary compromise. We found no risk factors for the progression of gastric adenocarcinoma to the lung or the pleura.

Gastric cancer was responsible for over 1,000,000 new cancer cases in 2020 and 768,793 deaths, making this cancer the fifth most frequently diagnosed and the fourth leading cause of cancer-related death. Incidence rates are markedly elevated in Eastern Asia, whereas the rates in Northern America and Northern Europe are generally low and are equivalent to those seen across the African regions [1]. After Eastern Asia and Eastern Europe, South America is one of the regions with the highest incidence of gastric cancer. The ASR per 100.000 population is between 18 and 39 for countries in Eastern Asia, such as Korea and Japan [1, 7]. In Latin America, high-risk pockets are reported in the Andes Mountains, with ASR between 13 and 17 for countries located in this zone, such as Chile and Colombia $[1,8]$. The incidence rates in Colombia vary with high-incidence areas located at high altitudes in the Andes Mountains and low-incidence areas on the coasts and valleys [2]. In the present cohort study, most patients come from high altitude regions close to Bogotá. This region is at 2,600m above sea level and has ASR similar to Japan and Korea, with values near 32.1 per 100.000 [2]. 
Tumor location in gastric cancer patients is different between Western and Eastern countries; tumors located in the proximal third are more frequent in western countries and this is associated with more advanced stage at presentation and worse survival $[7,9]$. Although Colombia has a high gastric cancer incidence in some territories, most patients are diagnosed at an advanced stage and their cancer's biological behavior is closer to that of western countries. In this cohort, more than half of our patients were diagnosed with a stage III disease; $25.8 \%$ had diffuse histology, and $13.8 \%$ were located in the cardias. Considering our findings, we believe that gastric cancer in western countries, including those from Latin America, has different biological behavior and therefore has different metastasis patterns compared to those reported in Eastern countries.

Distant metastasis does not usually reach the lungs and pleura, occurring in 0.3 to $6 \%$ of patients treated with curative intent [3]. This proportion was $3.1 \%$ in our series, but the proportion of patients with metastatic hematogenous seeding to the lung parenchyma was low, $0.22 \%$.

In United States, a multi-institutional analysis [10], including 817 patients with gastric cancer treated with curative intent showed that the most common sites of distant recurrence were peritoneum, followed by liver, lung, and bone. The median recurrence-free survival was 10.8 months, and the median time for lung recurrence was 10.1 months. They found several factors related to recurrence, including age, lesion size, histologic type, number of lymph node metastasis, and the presence of lymphovascular invasion or perineural invasion. The median survival after recurrence was five months, and only $2 \%$ developed pleuropulmonary metastases. In the present study, we did not find any risk factors for the gastric adenocarcinoma progression to the lung or pleura.

Survival after gastric cancer recurrence is low. Even with chemotherapy, the median survival ranges between 6 and 13 months [11]. The Memorial Sloan-Kettering Cancer Center study [4], representing a western cohort, described three recurrence patterns of adenocarcinoma: locoregional, peritoneal, and distant or systemic. From 1172 patients who underwent R0 resection, 42.3\% had a recurrence. Most recurrences (79\%) occurred in the first two years, and disease recurrence was rare after four years. Locoregional recurrences were present in $54 \%$, peritoneal recurrence in $29 \%$, and distant recurrences in $51 \%$. Only 39 patients had recurrences to the lung parenchyma, representing $3.3 \%$ of the entire cohort, similar to our study. The median time from recurrence to death was six months, $70 \%$ were dead within one year, and the specific recurrence pattern had no significant effect on the time to death.

The cohort study reported by Kong et al. in 2012 [5], representing an eastern cohort, reported the most extensive series to date; they reviewed 20.187 gastric cancer patients and identified $193(0.96 \%)$ as having metastases to the lung parenchyma, pleura, or lymphangitic metastatic lesions. Even though, the incidence of pleuro-pulmonary metastasis was $3.1 \%$ in our cohort, higher than that described by Kong et al. they found that the most frequent pattern of lung metastasis was hematogenous metastasis (44.5\%) followed by pleural (24.4\%), lymphangitic (18.7\%) and mixed (12.6\%) metastases. In our series, the main pattern of pleuro-pulmonary metastasis was lymphangitic metastasis present in $42.9 \%$ of the patients, followed by a mixed pattern in $28.6 \%$, pleural metastasis in $21.4 \%$ and only one patient $(0.2 \%)$ had 
hematogenous metastasis. They also found that young age was associated with the lymphangitic spread, and the diffuse type was associated with pleural seeding. This cohort is different from ours because it was not restricted to patients treated with curative intent. Finally, Kong et al. described that $80 \%$ of the patients with lung metastases of gastric cancer had concomitant metastases of other organs, especially the peritoneum and liver and they found that the median survival after diagnosing pleuropulmonary metastases in gastric cancer patients was four months, and 5-year survival was only $2-4 \%$. In our series, we did not describe the presence of concomitant metastases of other organs and the median survival after diagnosis of pleuro-pulmonary metastases was 1.1 months.

Aurello et al. [11] described that the median time to recurrence was 14 to 29 months after surgery, similar to what we found in our series, where the median time for developing pleuro-pulmonary metastases after gastric surgery was 22.3 months.

Lung metastasectomy has been proposed for several solid tumors, however, little is known about the resection of gastric cancer lung metastasis [3]. There are many series and case reports describing lung metastasectomy, especially in Asian countries [3, 12-14]. In 2010, Kemp et al. [13] addressed this question with a review of the articles on this subject published from 1975 to 2008 . They reported 21 studies, including 43 patients with overall survival or 39 months and five-year survival of $33 \%$ after lung metastasectomy and a median survival time of 29 months. Aurello et al. [3] performed a systematic review in 2016 that included 44 patients who underwent lung resection for gastric cancer metastasis between 1998 and 2013; after lung resection, recurrence occurred in 21 patients, and six patients were disease-free at the last follow-up; median overall survival after gastric resection 45 months, suggesting that lung metastasectomy could improve the survival of patients with lung metastasis from gastric cancer when compared to patients treated with palliative chemotherapy. Shiono et al. [13] reported a 5year overall survival of $28 \%$ for patients with gastric cancer treated with pulmonary metastasectomy and a median survival time of 29 months. The study by lijima et al. [14] reported ten patients who underwent pulmonary metastasectomy for gastric cancer in Japan; their primary disease was controlled, they had no other extrapulmonary metastases, and the pulmonary metastases were limited to one lung; the overall 3year survival was $30 \%$, and the median survival time following pulmonary resection was 26.8 months. In our study, the only patient who had lung metastasectomy survived for 32 months after gastrectomy and 12 months after pulmonary resection. We cannot make any conclusions with one patient, but the median survival after lung metastasis diagnosis and treatment was higher compared with patients with unresected pleuro-pulmonary compromise. The role of pulmonary metastasectomy in gastric cancer needs further studies, and it may be proposed only for selected cases.

Even though, thoracic staging with CT-scan for gastric adenocarcinoma is still controversial [15], we believe it is necessary. In patients with pleural or lymphangitic carcinomatosis, CT-scan findings are usually very suggestive of metastatic compromise. However, in the case of lung nodules, the incidence of metastatic lesions was very low and although this study looked at the development of pulmonary metastases after gastric cancer resection, not at diagnosis; these results may be a starting point for 
further studies in patients with pulmonary nodules at the time of diagnosis that may change the approach during gastric cancer staging and avoid unnecessary lung resections.

There are several limitations in this study. It was a retrospective analysis of a single institution and it did not describe which patients had concomitant metastatic sites other than the lung and pleura. However, this is the first study that describes the patterns of pleuro-pulmonary metastases in gastric cancer patients treated with curative intent in Latin-America.

\section{Conclusions}

Incidence of pleural or pulmonary metastases in patients with gastric adenocarcinoma treated with curative intent was low. In our series, lymphangitic metastasis was the main pattern of dissemination, meanwhile lung nodules with histopathologic confirmation of hematogenous metastasis were rare. Meanwhile, patients with pleural carcinomatosis had the lowest median survival, followed by patients with lymphangitic carcinomatosis. These findings and their prognosis were different compared to those reported in previous series in Eastern countries.

\section{Abbreviations}

ASIR

age-standardized incidence rate

ASMR

age-standardized cancer mortality rate

INC

Instituto Nacional de Cancerología

IQR

interquartile range

CT-scan

Computed tomography

PNI

Perineural invasion

LVI

lymphovascular invasion

IHC

immunohistochemistry

\section{Declarations}

\section{Ethics approval}


This study was performed in line with the principles of the Declaration of Helsinki. Approval was granted by the Ethics Committee of the Instituto Nacional de Cancerología in Colombia (Act No. 0023-19).

\section{Consent to participate}

Not applicable

\section{Consent for publication}

Not applicable

\section{Competing interests}

The authors declare that they have no competing interests

\section{Funding}

No funds, grants, or other support was received.

\section{Author contributions}

Conceptualization: Juliana Restrepo, Carlos Carvajal, Helena Facundo. Methodology: Carlos Carvajal, José Carreño. Formal analysis and investigation: Carlos Carvajal, José Carreño. Writing - original draft preparation: Juliana Restrepo, Felipe González, Ana María Ramírez, Andrés-Felipe Jimenez. Writing review and editing: Carlos Carvajal, Helena Facundo, Rafael Beltran, Ricardo Buitrago, Ricardo Oliveros. Supervision: Juliana Restrepo, Carlos Carvajal. All authors read and approved the final manuscript.

\section{Conflicts of Interest/Competing interests}

The authors have no relevant financial or non-financial interests to disclose.

\section{Availability of data and material}

The datasets generated and analyzed during the current study are available from the corresponding author on reasonable request.

\section{Acknowledgements}

Thank to Doctor Sandra Mosquera for the language and style revision.

\section{References}

1. Ferlay J, Ervik M, Lam F, Colombet M, Mery L, Piñeros M, Znaor A, Soerjomataram I, Bray F. (2020). Global Cancer Observatory: Cancer Today. Lyon, France: International Agency for Research on Cancer. Available from: https://gco.iarc.fr/today, accessed [21 June 2021]. 
2. Pardo $C$, Cendales R. Cancer incidence estimates and mortality for the top five cancer in Colombia, 2007-2011. Colomb Med (Cali). 2018 Mar 30;49(1):16-22. doi: 10.25100/cm.v49i1.3596. PMID: $29983460 ;$ PMCID: PMC6018817.

3. Aurello P, Petrucciani N, Giulitti D, Campanella L, D'Angelo F, Ramacciato G. Pulmonary metastases from gastric cancer: Is there any indication for lung metastasectomy? A systematic review. Med Oncol. 2016 Jan;33(1):9. doi:10.1007/s12032-015-0718-4. Epub 2015 Dec 26. PMID: 26708132.

4. D'Angelica M, Gonen M, Brennan MF, Turnbull AD, Bains M, Karpeh MS. Patterns of initial recurrence in completely resected gastric adenocarcinoma. Ann Surg. 2004 Nov;240(5):808-16. doi:10.1097/01.sla.0000143245.28656.15. PMID: 15492562; PMCID: PMC1356486.

5. Kong JH, Lee J, Yi CA, Park SH, Park JO, Park YS, Lim HY, Park KW, Kang WK. Lung metastases in metastatic gastric cancer: pattern of lung metastases and clinical outcome. Gastric Cancer. 2012 Jul;15(3):292-8. doi:10.1007/s10120-011-0104-7. Epub 2011 Oct 29. PMID: 22037917.

6. Bray F, Ferlay J, Soerjomataram I, Siegel RL, Torre LA, Jemal A. Global cancer statistics 2018: GLOBOCAN estimates of incidence and mortality worldwide for 36 cancers in 185 countries. CA Cancer J Clin. 2018 Nov;68(6):394-424. doi: 10.3322/caac.21492. Epub 2018 Sep 12. Erratum in: CA Cancer J Clin. 2020 Jul;70(4):313. PMID: 30207593.

7. Chan WL, Lam KO, Lee VHF, Davidson M, So TH, Li JS, Chau I, Kwong DLW. Gastric Cancer - From Aetiology to Management: Differences Between the East and the West. Clin Oncol (R Coll Radiol). 2019 Aug;31(8):570-577. doi: 10.1016/j.clon.2019.05.012. Epub 2019 Jun 7. PMID: 31178345.

8. Correa P. Gastric cancer: overview. Gastroenterol Clin North Am. 2013 Jun;42(2):211-7. doi: 10.1016/j.gtc.2013.01.002. Epub 2013 Feb 21. PMID: 23639637; PMCID: PMC3995345.

9. Ueno T, lida M, Yoshino S, Takeda S, Kubota H, Higashida M, Oka Y, Tsuruta A, Matsumoto H, Nagano H. East Versus West: Differences in Surgical Management in Asia Compared with Europe and North America. Surg Clin North Am. 2017 Apr;97(2):453-466. doi: 10.1016/j.suc.2016.12.002. PMID: 28325197.

10. Spolverato G, Ejaz A, Kim Y, Squires MH, Poultsides GA, Fields RC, Schmidt C, Weber SM, Votanopoulos K, Maithel SK, Pawlik TM. Rates and patterns of recurrence after curative intent resection for gastric cancer: a United States multi-institutional analysis. J Am Coll Surg. 2014 Oct;219(4):664-75. doi: 10.1016/j.jamcollsurg.2014.03.062. Epub 2014 Jun 26. PMID: 25154671.

11. Aurello P, Petrucciani N, Antolino L, Giulitti D, D'Angelo F, Ramacciato G. Follow-up after curative resection for gastric cancer: Is it time to tailor it? World J Gastroenterol. 2017 May 21;23(19):33793387. doi: 10.3748/wjg.v23.i19.3379. PMID: 28596674; PMCID: PMC5442074.

12. Kemp CD, Kitano M, Kerkar S, Ripley RT, Marquardt JU, Schrump DS, Avital I. Pulmonary resection for metastatic gastric cancer. J Thorac Oncol. 2010 Nov;5(11):1796-805. doi:10.1097/JTO.0b013e3181ed3514. PMID: 20881648; PMCID: PMC7367252.

13. Shiono S, Sato T, Horio H, Chida M, Matsuguma H, Ozeki Y, Nakajima J, Okumura S, Metastatic Lung Tumor Study Group of Japan. Outcomes and prognostic factors of survival after pulmonary 
resection for metastatic gastric cancer. Eur J Cardiothorac Surg. 2013 Jan;43(1):e13-6. doi:10.1093/ejcts/ezs574. Epub 2012 Nov 8. PMID: 23137557.

14. lijima $Y$, Akiyama $H$, Atari M, Fukuhara M, Nakajima $Y$, Kinosita H, Uramoto H. Pulmonary Resection for Metastatic Gastric Cancer. Ann Thorac Cardiovasc Surg. 2016 Aug 23;22(4):230-6. doi: 10.5761/atcs.oa.16-00049. Epub 2016 Apr 27. PMID: 27118522; PMCID: PMC5045850.

15. Chong CS, Ng CW, Shabbir A, Kono K, So JB. Computed tomography of the thorax for gastric cancer staging: Is it necessary? Scand J Surg. 2015 Dec;104(4):244-7. doi:10.1177/1457496915571400. Epub 2015 Feb 13. PMID: 25681056.

\section{Figures}

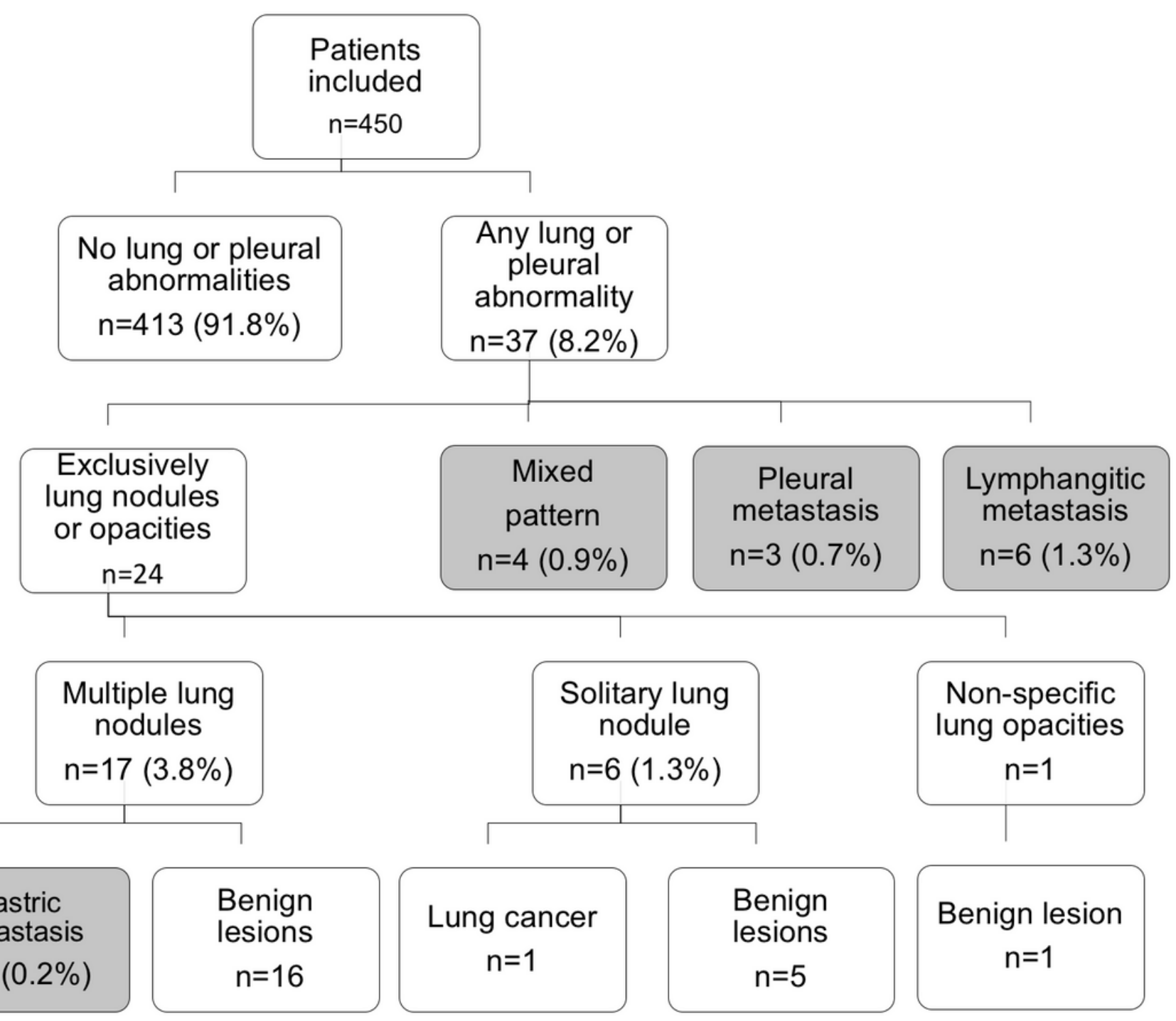

Figure 1

Flow chart of included patients 
a.

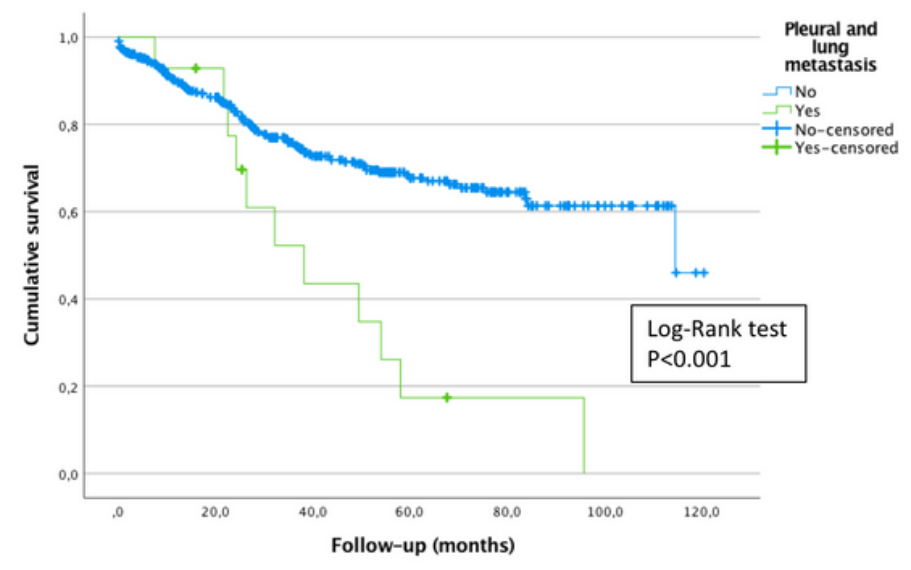

b.

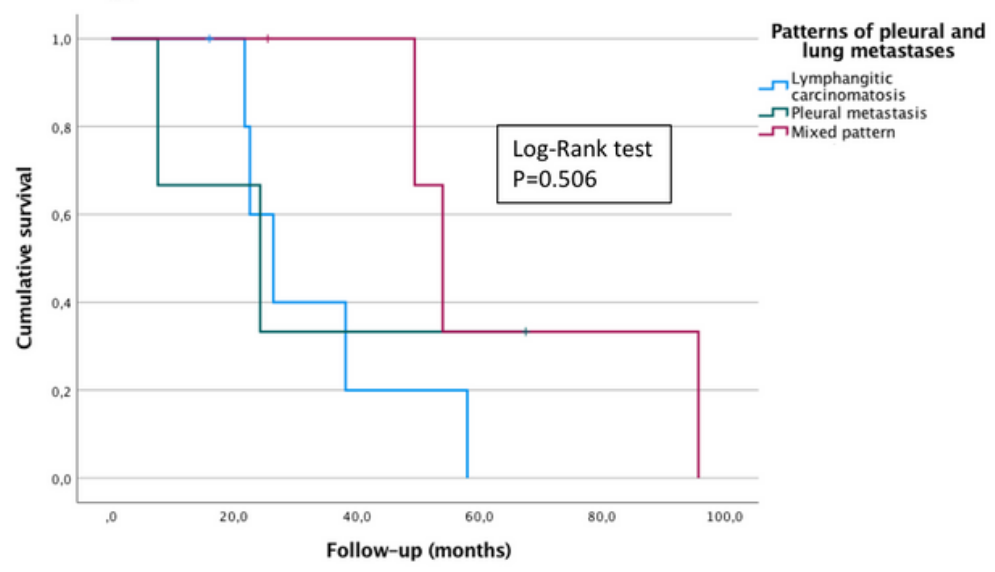

Figure 2

a Overall survival of gastric cancer patients treated with curative intent who had pleuro-pulmonary lung metastasis, Kaplan-Meier with Log-Rank test $\boldsymbol{b}$ Overall survival of patients according to metastasis pattern, Kaplan-Meier with Log-Rank test 